\title{
E-Katalog Dalam Pemasaran Barang/Jasa Pada Usaha Mikro Kecil Menengah (UMKM) Dalam Masa Pandemi Covid-19
}

\author{
Ahmad Suryono $^{1 *}$, Yeni Dwi Rahayu ${ }^{2}$, Milang Akbar Winasis ${ }^{3}$, M Faiz Nailil Murod $^{4}$ \\ ${ }_{1,2,3,4}$ Universitas Muhammadiyah Jember \\ 11ahmadsuryono@unmuhjember.ac.id, ${ }^{2}$ yenidwirahayu@ @unmuhjember.ac.id, ${ }^{3}$ milangakbar@gmail.com, ${ }^{4}$ failnailil@gmail.com
}

\begin{abstract}
Indonesia is one of the developing countries where economic growth in Indonesia is growing rapidly both materially and nonmaterially, this need can be in the form of procurement of goods / services. The challenge faced by micro, small and medium agro-industry players (MSMEs) is to maintain growth in local and global markets. With the Covid-19 pandemic this has also affected trade in Indonesia, namely the shifting behavior of trading patterns has changed, which was originally carried out directly (offline), now it is required to be indirect (online) so that the business continues. In realizing the success of achieving the vision in the economic sector at a broader level with the development of technology, especially in the procurement of goods / services quickly, precisely, transparently and efficiently in reaching customers. In Presidential Regulation No. 54 of 2010 concerning Government Procurement of Goods / Services, it is intended to facilitate MSMEs in carrying out marketing of goods I services through the E-Purchasing mechanism with the E-catalog system, to support government procurement in the era of the Internet of Things (IoT) to be aligned. with the changing times with the aim of making the organization more responsive, transparent and accessible so that checks and balances occur. This e-catalog is the government's way of encouraging MSMEs to rise again in the era of adapting to new habits or new normal to overcome the impact of decreased turnover in order to strengthen and empower MSMEs.
\end{abstract}

Keywords : UMKM, Marketing, E-katalog

\begin{abstract}
Abstrak
Indonesia merupakan salah satu negara berkembang yang dimana pertumbuhan ekonomi di indonesia berkembang pesat secara materiil maupun non materiil, kebutuhan tersebut dapat berupa pengadaan barang/jasa. Tantangan yang dihadapi pelaku agroindustri mikro kecil me-nengah (UMKM) adalah mempertahankan pertumbuhan di pasar lokal dan global. Dengan adanya pandemi Covid-19 ini juga telah berpengaruh terhadap perdagangan di Indonesia yakni adanya shifting behavior pola perdagangan menjadi berubah, yang semula dilakukan secara langsung (offline), saat ini dituntut untuk menjadi tidak langsung (online) agar usahanya tetap berjalan. Dalam mewujudkan keberhasilan pencapaian visi dalam sektor perekonomian pada tingkat yang lebih luas lagi dengan berkembangnya teknologi khususnya dalam pengadaan barang/jasa secara cepat, tepat, transparasi dan efisien dalam menjangkau costumer. Dalam Peraturan Presiden No 54 tahun 2010 tentang Pengadaan Barang/Jasa Pemerintah ini ditujukan untuk mempermudah UMKM dalam menjalankan pemasaran barang/jasa dengan melalui mekanisme E-Purchasing dengan sistem E-katalog, untuk menunjang pengadaan pemerintah pada era internet of Things (IoT) agar selaras dengan perkembangan jaman dengan tujuan agar organisasi lebih responsif, transparan dan accessible sehingga terjadi check and balance. E-katalog ini merupakan cara pemerintah dalam mendorong UMKM kembali bangkit di era adaptasi kebiasaan baru atau new normal untuk menganggulangi dampak penurunan omset guna memperkokoh dan memberdayakan UMKM.
\end{abstract}

Kata Kunci: UMKM, Pemasaran, E-Katalog

*Penulis Korespondensi : Ahmad Suryono 


\section{Pendahuluan}

Indonesia merupakan salah satu negara berkembang yang dimana pertumbuhan ekonomi di indonesia berkembang pesat secara materiil maupun non materiil, kebutuhan tersebut dapat berupa pengadaan barang/jasa. Usaha mikro kecil dan menegah (UMKM) merupakan salah satu kegiatan yang melibatkan masyarakat Indonesia, UMKM ini memiliki kontribusi dalam penyerapan tenaga kerja, pembentukan Produk Domestik Bruto (PDB), nilai ekspor nasional dan investasi nasional.

Pada saat ini dengan berlangsungnya pembatasan sosial bersekala besar (PSBB) akibat COVID-19 yang membuat perekonomian di indonesia melemah, ini menjadikan keadaan UMKM sendiri mengalami penurunan pada pemasukan sehingga banyak dari mereka mengalami kerugian. Tantangan yang dihadapi pelaku agroindustri mikro kecil me-nengah (UMKM) adalah mempertahankan pertumbuhan di pasar lokal dan global. Dalam mewujudkan keberhasilan pencapaian visi dalam sektor perekonomian pada tingkat yang lebih luas lagi dengan berkembangnya teknologi khususnya dalam pengadaan barang/jasa secara cepat, tepat, transparasi dan efisien dalam menjangkau costumer. Pada pengadaan barang/jasa secara elektronik ini telah diatur pada Peraturan Presiden No 54 Tahun 2010 tentang Pengadaan Barang/Jasa Pemerintah.

Pada UMKM saat ini penjualan di era digital sangat penting untuk mengatasi permasalah yang sering mereka alami tentang bagaimana mengenal target pasar serta untuk lebih mengembangkan usaha dan meminimalisir hilangnya konsumen, dengan ini diharapkan UMKM dapat melihat peluang dan potensi mereka. Dalam Peraturan Presiden No 54 tahun 2010 tentang Pengadaan Barang/Jasa Pemerintah ini ditujukan untuk mempermudah UMKM dalam menjalankan pemasaran barang/jasa dengan melalui mekanisme E-Purchasing dengan sistem E-katalog untuk menunjang pengadaan pemerintah pada era internet of Things (IoT) agar selaras dengan perkembangan jaman dengan tujuan agar organisasi lebih responsif, transparan dan accessible sehingga terjadi check and balance. Berdasarkan permasalah yang telah diuraikan sebelumnya, yang pada intinya adalah penurunan omset karena kondisi pandemic saat ini dan kurangnya pengetahuan dalam pemasaran produk era digital. Masalah tersebut harus segera diselesaikan untuk memaksimalkan daya saing.

Dengan adanya inovasi berupa E-katalong ini, diharapkan pendapatan UMKM dapat meningkat. Berbeda dengan apabila barang/jasa yang dijual secara langsung (offline). Kemungkinan yang terjadi apabila barang/jasa dijual secara langsung (offline) barang/jasa tersebut tidak dapat mengenal target pasar dan potensi.

\section{Metode}

Pengabdian dilaksanakan bersama dirumah mitra Jalan rembangan, Rt 01/Rw 04, Kecamatan Patrang. Masalah yang dihadapi oleh UMKM, dapat diselesaikan dengan cara dilakukannya koordinasi antara pengusul yakni KLDI dan penyedia dengan LKPP. Beberapa metode yang digunakan untuk memecahkan masalah yaitu: (1) menyelenggarakan pelatihan/praktik pengoprasian E-katalog, (2) mendampingi proses pembuatan E-katalog (3) mendampingi mitra dalam pendaftaran E-katalog dalam barang/jasa UMKM. KLDI dan penyedia secara aktif berkoordinasi dengan LKPP. Koordinasi dilakukan dalam rangka penyelesaian masalah yang dihadapi oleh UMKM.

Pentingnya koordinasi disebabkan karena para LKPP memiliki informasi secara mendalam mengenai kondisi dan masalah pada pemasaran. Terkait dengan tempat koordinasi. Pada tahap persiapan melaksanakan koordinasi dengan mitra, mengidentifikasi permasalahan mitra, menyusun modul, sosialisasi kepada peserta, mengadakan koordinasi dengan UMKM, masyarakat. Kemudian tahap pelaksanaan, meliputi kegiatan pelaksanaan pelatihan, simulasi kegiatan, pembuatan video kegiatan.

Terakhir tahap evaluasi, penyusunan laporan kegiatan, pembuatan laporan, publikasi kegiatan, pembuatan artikel. Adapun rencana kegiatan, PKM akan dilaksanakan selama 3-6 bulan yang meliputi tahap persiapan pelatihan (melaksanakan koordinasi dengan mitra, mengidentifikasi permasalahan mitra, menyusun 
modul, sosialisasi kepada peserta, mengadakan koordinasi UMKM maupun masyarakat.

\section{Hasil dan Pembahasan}

Hasil pengabdian masyarakat adalah terciptanya sebuah E-katalog bagi UMKM yang berfungsi untuk mempermudah dan meningkatkan volume perdagangan dari mitra. Adapun hasil pengabdian masyarakat terdiri dari beberapa bagian yang terdiri dari : nama produk, mekanisme penggunaan produk dan manfaat penggunaan produk.

1. Nama Produk

Nama produk hasil pengabdian masyarakat adalah E-katalog di laman web http://36.66.192.46/spreiku.

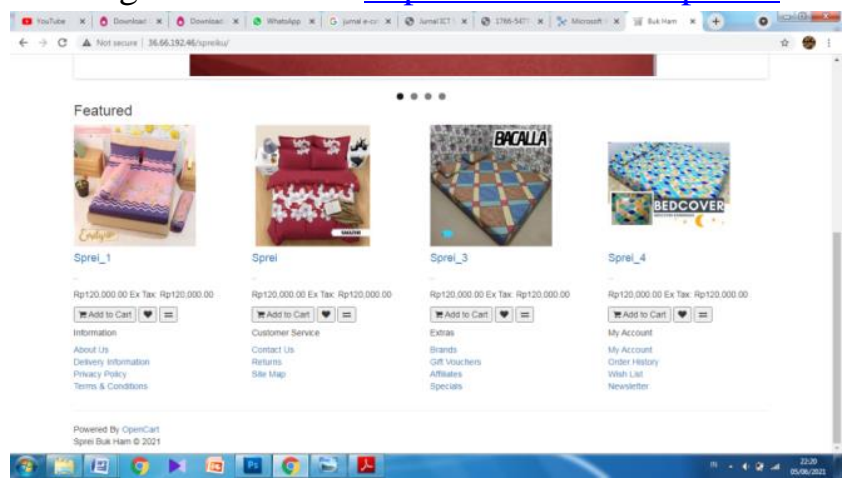

Gambar 1. Menu Utama

2. Mekanisme Penggunaan Produk

Produk pengabdian masyarakat berisi catalog dalam bentuk digital yang berisi produk sprei dan bed cover dari UMKM "buk ham" dengan berbagai varian jenis, desain, warna, ukuran dan harga. Varian-varian tersebut akan mengalami fluktuasi secara periodik, baik harga, jenis dan ketersediaannya, sehingga membutuhkan update secara berkala. Kehadiran produk e-katalog akan sangat membantu UMKM "buk ham" dalam melakukan perubahan secara berkala karena jenis produk yang ditawarkan sangat banyak dan beragam. Dengan model e-katalog, maka kendala waktu dan ketepatan serta ketelitian dalam melakukan update produk dapat teratasi sehingga memudahkan mitra dalam melakukan transaksi, sekaligus mengetahui barang mana saja yang terjual, masih ada dan/atau out of stock.

Produk akan digunakan oleh mitra secara periodik dengan hanya melakukan update pada varian dan jenis tertentu, yang berkaitan dengan ketersediaan barang, fluktuasi harga dan ketersediaan varian. Produk pengabdian masyarakatakan sangat membantu mitra karena tidak perlu repot dalam melakukan updating barang dagangan secara manual melalui medium Whatss App (WA). Dengan demikian mitra dapat terbantu bukan hanya terkait dengan tampilan, namun juga terkait manajemen stok dan manajemen keuangan.

3. Manfaat Pengunaan Produk

Produk pengabdian masyarakatakan membantu mitra untuk melakukan evaluasi produk, evaluasi penjualan dan evaluasi keuangan. Dengan adanya produk inimitra akan tampil lebih profesional dan lebih banyak menjangkau pasar secara sistematis dan massif. Dengan demikian diharapkan mitradapat tumbuh lebih besar dan menginspirasi tumbuhnya UMKM lainnya.

Pada pemakaian program ini pembeli terdapat sistem login dan pendaftaran pada tahap awal untuk masuk ketahap pencarian barang, terdapat pemisahan kategori barang yang memudahkan dalam proses pemilihan serta terdapat konfirmasi orderan secara bertahap.

\section{Kesimpulan}

Produk e-katalog bagi mitra akan sangat berguna baik secara internal maupun eksternal. Terlebih di masa pandemi, produk ini tidak hanya akan membantu mitra bertahan di tengah pandemi, namun bisa jadi akan membantu mitra memperluas pasar dan jangkauan pasar. Termasuk juga mengidentifikasi pembeli dan pola pembelian serta karakteristik konsumen. Manfaat produk ini akan paripurna karena menyangkut aspek hulu sampai hilir.

\section{UCAPAN TERIMA KASIH}

Tim pengabdian E-katalog dalam pemasaran barang/jasa pada usaha mikro menengah (umkm) dalam masa pandemi covid-19 mengucapkan terimakasih yang sebesar-besarnya kepada mitra yang telah bersedia mengikuti proses pengabdian. 


\section{DAFTAR PUSTAKA}

Undang Undang Nomor 20 Tahun 2008 tentang Usaha Mikro, Kecil Dan Menengah, Lembaran Negara Nomor 93Tahun 2008

Muhammad Iqbal. 2020. Pengaruh Pelaksanaan E-Katalog Dalam PengadaanBarang/Jasa Pemerintah Terhadap UMKM. Journal. Universitas Semarang.

Dina Yulistina Baiq dan Desi Dwi Arianti. 2019. E-Katalog Sebagai Sistem Informasi Pemasaran Kopi Sapit Berbasis Web. Universitas Hamzanwadi AR.

Indra Syahbandar. 2017. Media Promosi Meubel Berbasis ECatalogue. STMIK - IKMI Cirebon.

Relung Halim. 2013. Pembuatan E-Katalog Dan E-Lelang Pada Sistem Android. Universitas Surabaya. 